\title{
Heat Characteristics and Performance of Longitudinal Fin Exposed to Wet Air
}

\author{
Ziad M. Al-Makhyoul \\ Lecturer \\ Department of Mechanical Engineering-University of Mosul-Iraq
}

\begin{abstract}
A numerical study of the performance of longitudinal fin exposed to wet air has been carried out using finite difference technique. The temperature distribution over the fin surface was determined by using a third-degree polynomial correlation for the relationship between dry bulb temperature and humidity ratio for the saturated air at relative humidity of $(0,25,50$ and 100$) \%$ and length of fin from $(0.01$ to 0.1$) \mathrm{m}$. Also, fin efficiency, fin effectiveness and heat transfer have been calculated. The effect of the atmospheric pressure was also considered. The study showed that the fin effectiveness and fin efficiency of a fin in the case of fully wet fin was found to be smaller than those in the dry fin and the temperature gradient at the tip for a dry fin was greater than that for the wet fin.
\end{abstract}

Key words: Longitudinal fins, relative humidity, heat transfer

$$
\begin{aligned}
& \text { خصائص الحرارة وأداء زعنفة طولية معرضة لهواء رطب } \\
& \text { زياد محمد مجيد المخيول } \\
& \text { مدرس } \\
& \text { قسم الهندسة الميكانيكية - جامعة الموصل - العراق }
\end{aligned}
$$

\section{الخلاصة}

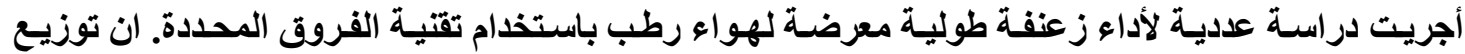

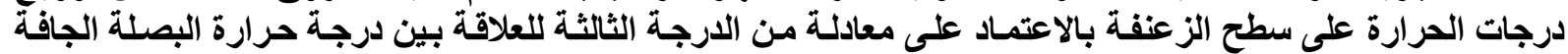

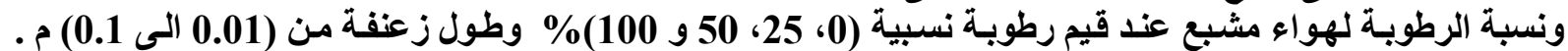

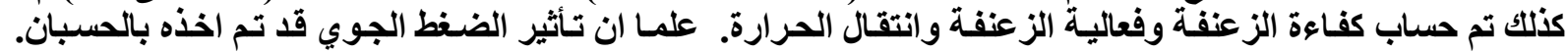

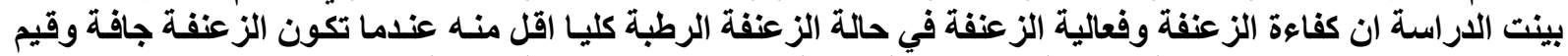

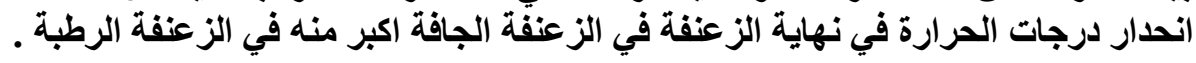

$$
\text { الكلمات المفتاحية: زعانف طولية ، الرطوبة النسبية ، انتقال الحرارة }
$$




\section{Nomenclature}

\begin{tabular}{|c|c|c|}
\hline A & Fin surface area & $\mathrm{m}^{2}$ \\
\hline $\mathrm{Cp}$ & Specific heat of moist air & $\mathrm{kJ} /\left(\mathrm{kg} .{ }^{\circ} \mathrm{K}\right)$ \\
\hline $\mathrm{H}$ & Width of fin & $\mathrm{m}$ \\
\hline $\mathrm{H}$ & Heat transfer coefficient & $\mathrm{W} / \mathrm{m}^{2} \cdot{ }^{\circ} \mathrm{K}$ \\
\hline$h_{\text {fg }}$ & Latent heat of condensation $\left(\mathrm{h}_{\mathrm{fg}}=2430\right)$ & $\mathrm{kJ} / \mathrm{kg}$ \\
\hline $\mathrm{h}_{\mathrm{m}}$ & Mass transfer coefficient & $\mathrm{W} / \mathrm{m}^{2} \cdot{ }^{\circ} \mathrm{K}$ \\
\hline $\mathrm{K}$ & Thermal conductivity for the fin (copper material, $\mathrm{k}=400$ ) & $\mathrm{W} / \mathrm{m} .{ }^{\circ} \mathrm{K}$ \\
\hline Le & Lewis number & ------- \\
\hline Lf & Length of fin & $\mathrm{m}$ \\
\hline $\mathrm{M}, \mathrm{N}$ & Number of grid in radial and transverse directions & ------- \\
\hline $\mathrm{P}_{\mathrm{atm}}$ & Atmospheric pressure & Bar \\
\hline $\mathrm{P}_{\mathrm{s}}$ & Pressure at saturated temperature & Bar \\
\hline $\mathrm{P}_{\mathrm{v}}$ & Water vapour pressure & Bar \\
\hline $\mathrm{QF}_{\mathrm{n}}$ & Heat transfer from fin numerically & $\mathrm{W}$ \\
\hline $\mathrm{QF}_{\text {MAX }}$ & Maximum heat transfer & $\mathrm{W}$ \\
\hline QNF & Heat transfer at the base without fin & $\mathrm{W}$ \\
\hline$X$ & The distance on length of fin & $\mathrm{m}$ \\
\hline $\mathrm{Y}$ & The distance in transverse direction of fin & $\mathrm{m}$ \\
\hline $\mathrm{RH}$ & Relative humidity & $\%$ \\
\hline $\mathrm{T}_{\mathrm{s}}$ & Surface temperature of fin & ${ }^{\circ} \mathrm{C}$ \\
\hline $\mathrm{T}_{\mathrm{b}}$ & Base temperature of fin & ${ }^{\circ} \mathrm{C}$ \\
\hline $\mathrm{T}_{\mathrm{f}}$ & Fluid temperature & ${ }^{\circ} \mathrm{C}$ \\
\hline $\mathrm{W}$ & Thickness of fin & $\mathrm{m}$ \\
\hline Wo & (SOR) factor & ------- \\
\hline$\varepsilon$ & Fin effectiveness & ------- \\
\hline$\eta_{\mathrm{f}}$ & Fin efficiency & ------- \\
\hline$\theta$ & Dimensionless local fin surface temperature $\left(T_{f}-T_{s}\right) /\left(T_{f}-T_{b}\right)$ & ------- \\
\hline$\omega_{\mathrm{f}}$ & Humidity ratio of air & $\mathrm{kg}_{\mathrm{v}} / \mathrm{kg}_{\mathrm{a}}$ \\
\hline$\omega_{\mathrm{s}}$ & Humidity ratio of the fin surface & $\mathrm{kg}_{\mathrm{v}} / \mathrm{kg}_{\mathrm{a}}$ \\
\hline$\beta$ & Parameter defined as $\mathrm{h}_{\mathrm{fg}} /\left(\mathrm{cp} * \mathrm{Le}^{2 / 3}\right)$ & ${ }^{\circ} \mathrm{K}$ \\
\hline
\end{tabular}

\section{Introduction:}

Finned heat transfer surfaces are widely used in many industrial applications such as, air conditioning, refrigeration and chemical processing systems. In cooling and dehumidification processes heat and mass transfer occurs simultaneously when the coil surface temperature is below the dew point temperature of air being cooled. Several attempts have been made to analyze the fin efficiency with condensation of moist air [6].

Several researchers have investigated the effect of variable thermal properties on the performance of fins. Rosario and Rahman [1] carried out the first extensive analysis. They investigated the radial fin assembly under fully wet operating conditions and assumed a fixed sensible to total heat ratio to obtain their numerical solution. Their results showed that there was a strong relationship between the fin efficiency and relative humidity of the incoming air.

$\mathrm{Wu}$ and Bong [2] provided an analytical solution for the efficiency of a straight fin under both fully wet and partially wet conditions using the temperature and humidity ratio differences as the driving forces for heat and mass transfer. They assumed linear relationship 
between the humidity ratios of the saturated air on the fin surface. Their results showed that there was no much change of the fin efficiency with the relative humidity.

Kundu [3] analyzed analytically the fin performances of longitudinal wet fins of different profiles. In this connection, it can be mentioned that the consideration of linear relationship is an approximate. The incoming air near the fin surface became saturated during condensation. Therefore, the specific humidity of air on the fin surface varied with temperature according to the psychrometric variation which followed a process along the saturation curve on the psychrometric chart. It is well known that the saturation curve on the psychrometric chart is a curvilinear in nature. Therefore, the fin efficiency with linear relationship may be associated with an erroneous prediction.

Kundu and Das [4] developed a generalized analytical technique for longitudinal, and spine fins under dry and fully wet conditions. Their mathematical formulation was based on the assumption of a linear relationship between temperature and specific humidity, while the method of Frobenius power series expansion has been used to solve the governing differential equation.

Naphon [5] theoretically investigated the temperature distribution along an annular fin of constant thickness under dry-surface, partially wet-surface, and fully wet-surface conditions. The mathematical models based on the conservation equations of energy and mass were developed and solved by the central finite difference method to obtain the temperature distribution along the fin. His results agreed with other models.

Sharqawy and Zubair [6] studied analytically the efficiency and optimization of one dimensional heat transfer of longitudinal fin with combined heat and mass transfer. They introduced a new modified fin parameter calculated without knowing the actual fin-tip condition. Recently, the analysis of annular fins of constant cross-sectional in one dimensional heat flow area with the combined heat and mass transfer mechanisms has been demonstrated by Sharqawy and Zubair [7] analytically.

Kundu and Barman [8] investigated numerically the temperature distribution and efficiency of one dimensional annular fin rectangular profile. They employed a cubic polynomial relationship between specific humidity and temperature for betterment of mass transfer effect on thermal analysis of wet annular fins under dehumidifying conditions.

Goodarzian H. et. all [9] carried out a study of efficiency of straight fins for different configurations when subjected to simultaneous heat and mass transfer mechanisms analytically .The temperature and humidity ratio differences are the driving forces for heat and mass transfer, respectively. The solutions were obtained for temperature distribution over the fin surface when the fin was fully wet. This study used collocation method to obtain the temperature distribution on the fin. The results indicated that this method is very easy, concise and applicable.

Jin-Feng M. et al. [10] studied analytically and numerically the optimization on a straight rectangular fin in 1-D solution by applying the psychometric correlation of an airwater vapor mixture. The optimum dimensionless fin thickness was solved out through Fibonacci method. The result showed that the temperature difference between the base and the tip of the fin increased with the increase of relative humidity.

Jin Feng M. et al. [11] studied the efficiency of straight rectangular fin with combined heat and mass transfer. The numerical solution was carried out to obtain the fin efficiency in (2-D) solution using (SOR) method depending on local Biot number. The study included the conditions when the fin surface is dry, fully wet and partially wet and applying the psychometric correlation of an air-water vapor mixture. It was found that the critical air 
relative humidity became closer to air saturated humidity when local Biot number was increased.

Most on 1-D and 2-D heat and mass transfer models in released literature were based on analytical function assumption between temperature and humidity ratio, which made analytical solution easy to obtain. For rectangular fins, (2-D) heat and mass transfer process became complicated when subjected to natural convection with assumption of psychometric function and the (2-D) model equation became (2-D) Poisson equation, analytical solution could not be acquired directly. While the researchers [11 and 12] studied numerically the performance of straight fin depending on the assumptions of psychometric function. The present work is concerning with study of the performance of straight fin depended on a thirddegree polynomial correlation given by [4] for the relationship between the dry bulb temperature and humidity ratio of the saturated air.

\section{Analysis:}

A steady state case is carried out on (2D) longitudinal fin exposed to moving air stream as shown in figure (1).

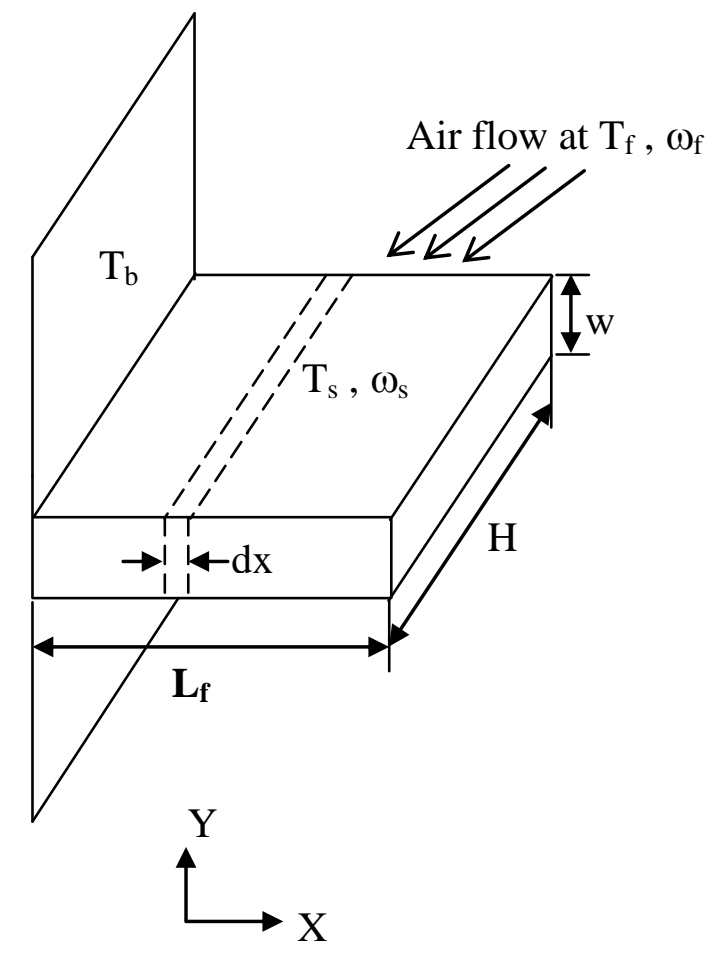

Figure (1) Schematic diagram of longitudinal fin exposed to fully wet air conditions.

This model depends on some assumptions to simplify the solution, these assumptions are:

1-Thermal conductivity of fin material is constant.

2-Pressure, temperature and relative humidity of the surrounding air are constant.

3-Fin base temperature is constant.

4- Effect of pressure drop of air due to airflow is neglected.

5-Heat flow and temperature distributions throughout the fin are independent of time. 
6-There is no heat source inside the fin.

7-Conductive heat and mass transfer coefficients are constant.

The fin surface can be classified as fully dry and fully wet. When the temperatures over the entire surface of the fin are higher than the dew point temperature of the surrounding air, then the surface is called fully dry and no humidification occurs. The fin surface will be fully wet when the temperatures over the entire fin surface are lower than the dew point of the air and simultaneous heat and mass transfer takes place [4]. In the present work, the temperature at every point on fin surface is assumed to be below the dew point temperature of the surrounding air.

\section{The Mathematical and Numerical Solution:}

For longitudinal fin, the fin was divided to longitudinal and transverse directions of $(\mathrm{N}$ and $\mathrm{M})$ divisions. The thickness of each division is $(\Delta \mathrm{x})$ in the longitudinal direction and $(\Delta y)$ in the transverse direction. The general equation for the temperature distribution in the two-dimensional heat flow case can be shown as:

$\frac{\partial^{2} \mathrm{~T}}{\partial \mathrm{x}^{2}}+\frac{\partial^{2} \mathrm{~T}}{\partial \mathrm{y}^{2}}=0$

The following boundary conditions are applied to the above equation :

$\frac{\partial T}{\partial \mathrm{x}}=0$ at the tip of fin, $\frac{\partial \mathrm{T}}{\partial \mathrm{y}}=0$ at center line of fin and $\mathrm{T}=\mathrm{T}_{\mathrm{b}}$ at the base of fin while the boundary condition at the surface of fin is:

$$
-\mathrm{k} \frac{\partial \mathrm{T}}{\partial \mathrm{y}}=\mathrm{h}\left(\mathrm{T}_{\mathrm{f}}-\mathrm{T}_{\mathrm{s}}\right)+\mathrm{h}_{\mathrm{fg}} \cdot \mathrm{h}_{\mathrm{m}}\left(\omega_{\mathrm{f}}-\omega_{\mathrm{s}}\right)
$$

Where $\omega_{\mathrm{f}}$ is the humidity ratio of air, $\omega_{\mathrm{s}}$ is the humidity ratio on the fin surface, $\mathrm{h}_{\mathrm{m}}$ is the mass transfer coefficient, $\mathrm{h}_{\mathrm{fg}}$ is the latent heat of condensation.

The saturated humidity ratio on the surface of fin $\omega_{\mathrm{s}}$ can be calculated from the correlation given by [4] :

$\omega_{\mathrm{s}}=\left(3.744+0.3078 * \mathrm{~T}_{\mathrm{s}}+0.0046 * \mathrm{~T}_{\mathrm{s}}^{2}+0.0004 * \mathrm{~T}_{\mathrm{s}}^{3}\right) \times 10^{-3}$

when $0^{\circ} \mathrm{C}<\mathrm{T}_{\mathrm{f}}<30^{\circ} \mathrm{C}$

According to Chilton-Colburn analogue [11], the relation between the heat transfer coefficient and mass transfer coefficient is:

$\frac{\mathrm{h}}{\mathrm{h}_{\mathrm{m}}}=\mathrm{Cp} \times \mathrm{Le}^{\frac{2}{3}}$

Therefore, for the energy balance in equation (2) yields the following differential equation:

$$
\begin{aligned}
& -\mathrm{k} \frac{\partial \mathrm{T}}{\partial \mathrm{y}}=\mathrm{h}\left[\left(\mathrm{T}_{\mathrm{f}}-\mathrm{T}_{\mathrm{s}}\right)+\frac{\mathrm{h}_{\mathrm{m}}}{\mathrm{h}} \times \mathrm{h}_{\mathrm{fg}} \times\left(\omega_{\mathrm{f}}-\omega_{\mathrm{s}}\right)\right] \\
& -\mathrm{k} \frac{\partial \mathrm{T}}{\partial \mathrm{y}}=\mathrm{h}\left[\left(\mathrm{T}_{\mathrm{f}}-\mathrm{T}_{\mathrm{s}}\right)+\frac{\mathrm{h}_{\mathrm{fg}}}{\mathrm{cp} \times \mathrm{Le}^{\frac{2}{3}}} \times\left(\omega_{\mathrm{f}}-\omega_{\mathrm{s}}\right)\right]
\end{aligned}
$$

and then:

$-\mathrm{k} \frac{\partial \mathrm{T}}{\partial \mathrm{y}}=\mathrm{h}\left[\left(\mathrm{T}_{\mathrm{f}}-\mathrm{T}_{\mathrm{s}}\right)+\beta \times\left(\omega_{\mathrm{f}}-\omega_{\mathrm{s}}\right)\right]$ 
Latent heat of the water evaporation, hfg, Lewis number, Le, and specific heat of air, Cp, can be assumed constant. Thus, $\beta$, can be considered as a constant $[5,7,8,9]$.

$\omega_{\mathrm{f}}=0.622 \times \frac{\mathrm{P}_{\mathrm{v}}}{\mathrm{P}_{\mathrm{atm}}}$

$\mathrm{P}_{\mathrm{v}}=\mathrm{RH} \times \mathrm{P}_{\mathrm{s}}$

Then, $\omega_{\mathrm{f}}=0.622 \times \frac{\mathrm{P}_{\mathrm{s}} \times \mathrm{RH}}{\mathrm{P}_{\mathrm{atm}}}$

Depending on basic equation (1) for longitudinal fin, the internal nodes for the temperature distribution can be calculated as:

$$
T(i, j)=\frac{\left(\frac{T(i+1, j)+T(i-1, j)}{\Delta x^{2}}+\frac{T(i, j+1)+T(i, j-1)}{\Delta y^{2}}\right)}{2\left(\frac{1}{\Delta x^{2}}+\frac{1}{\Delta y^{2}}\right)}
$$

When $1<\mathrm{i}<\mathrm{N}$ and $1<\mathrm{j}<\mathrm{M}$

The temperature distribution in the axis that divided the fin into two similar parts can be investigated as:

$$
\begin{aligned}
& \frac{\partial \mathrm{T}}{\partial \mathrm{y}}=0 \\
& \mathrm{~T}(\mathrm{i}, 1)=\frac{4 \mathrm{~T}(\mathrm{i}, 2)-\mathrm{T}(\mathrm{i}, 3)}{3}
\end{aligned}
$$

When $2<\mathrm{i}<\mathrm{N}-1$

For the fin tip, the formula is:

$T(N, j)=\frac{4 T(N-1, j)-T(N-2, j)}{2 \Delta x}$

For the fin surface:

$$
\begin{aligned}
& \mathrm{T}(\mathrm{i}, \mathrm{M})=\left[\frac{1}{2 \in \Delta \mathrm{y}+3}\right](-4 \mathrm{~T}(\mathrm{i}, \mathrm{M}-1)+\mathrm{T}(\mathrm{i}, \mathrm{M}-2))+\frac{\mathrm{T}_{\mathrm{f}}}{1+\left(\frac{3}{2 \in \mathrm{i} \Delta \mathrm{y}}\right)} \\
& \in=\mathrm{h}\left(1+\beta\left(\omega_{\mathrm{f}}-\omega_{\mathrm{s}}\right)\right)
\end{aligned}
$$

and for the symmetry line :

$\mathrm{T}(\mathrm{i}, 1)=\frac{4 \mathrm{~T}(\mathrm{i}, 2)-\mathrm{T}(\mathrm{i}, 3)}{3}$

The above system of equations is solved using the successive over relaxation (SOR) method which can be written as:

$\mathrm{TN}(\mathrm{i}, \mathrm{j})=\mathrm{T}(\mathrm{i}, \mathrm{j})+\mathrm{Wo}(\mathrm{TN}(\mathrm{i}, \mathrm{j})-\mathrm{T}(\mathrm{i}, \mathrm{j}))$

When $\mathrm{TN}(\mathrm{i}, \mathrm{j})$ represents a new temperature, $\mathrm{T}(\mathrm{i}, \mathrm{j})$ is the old temperature and $(\mathrm{Wo})$ is (SOR) factor. the program was more stable when (SOR) factor was (1.6) and this clear in figure (2). 


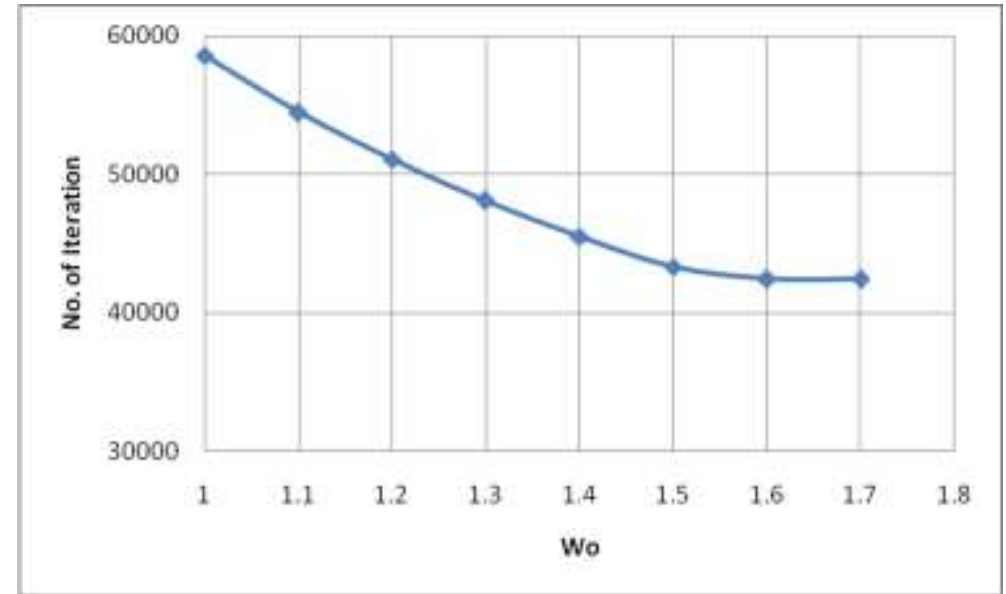

Figure (2). The relation between the iteration number of the program and (SOR) factor.

The heat dissipation by the fin is obtained from the summation of the flux over the fin surface, i.e.:

$$
\begin{aligned}
& \mathrm{QF}_{\mathrm{n}}=\sum_{\mathrm{i}=1}^{\mathrm{i}=\mathrm{N}} \mathrm{H} * \Delta \mathrm{x}(\mathrm{i}) * \mathrm{~h} *\left(\left(\mathrm{~T}_{\mathrm{f}}-\mathrm{T}(\mathrm{i}, \mathrm{M})+\beta *\left(\omega_{\mathrm{f}}-\omega_{\mathrm{s}}\right)\right)\right. \\
& \mathrm{QF}_{\mathrm{MAX}}=\sum_{\mathrm{i}=1}^{\mathrm{i}=\mathrm{N}} \mathrm{H} * \Delta \mathrm{x}(\mathrm{i}) * \mathrm{~h} *\left(\left(\mathrm{~T}_{\mathrm{f}}-\mathrm{T}(1,1)+\beta *\left(\omega_{\mathrm{f}}-\omega_{\mathrm{s}}\right)\right)\right. \\
& \mathrm{QNF}=\sum_{\mathrm{i}=1}^{\mathrm{i}=\mathrm{N}} \mathrm{H} * \mathrm{~W} * \mathrm{~h} *\left(\left(\mathrm{~T}_{\mathrm{f}}-\mathrm{T}(1,1)\right)\right.
\end{aligned}
$$

The fin efficiency and fin effectiveness are calculated as:

$$
\eta_{\mathrm{f}}=\frac{\mathrm{QF}_{\mathrm{n}}}{\mathrm{QF}_{\mathrm{MAX}}}, \varepsilon=\frac{\mathrm{QF}_{\mathrm{n}}}{\mathrm{QNF}}
$$

\section{Results and discussions:}

In the figure (3), the temperature distribution over the fin surface is plotted against the dimensionless distance $\mathrm{L}_{\mathrm{f}}=(\mathrm{x} / \mathrm{L})$ for relative humidity $\mathrm{RH}=(0$, 25,50 and 100) $\%$ for longitudinal fin of constant thickness. For these four values of relative humidity, the fin tip temperature is below the dew point of the air, therefore, the fin is fully wet. It can be seen that at the same location on the fin, the temperature dimensionless

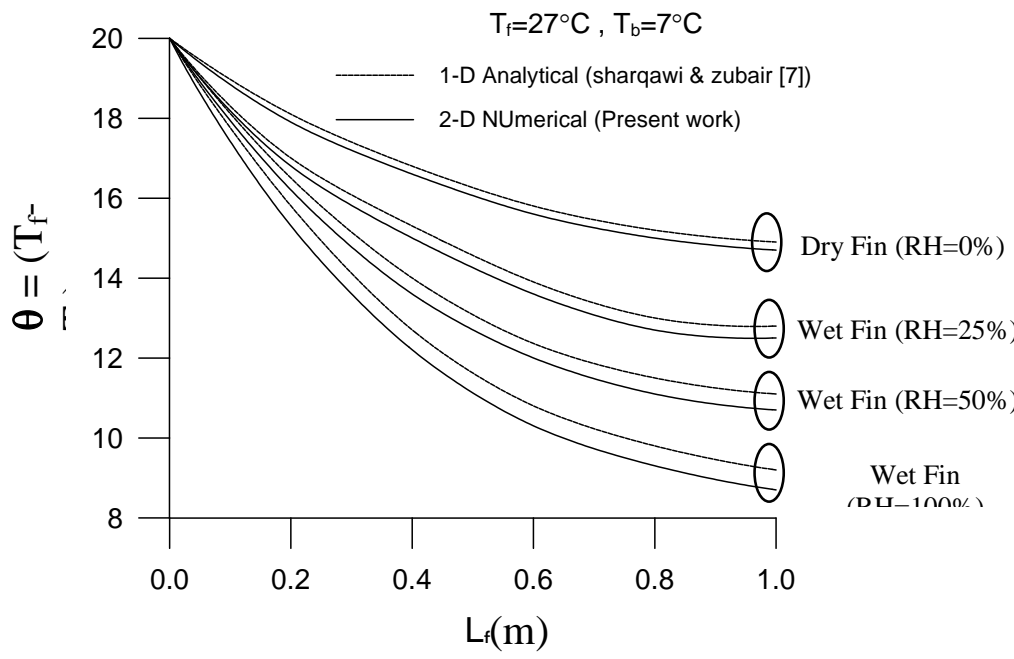

Figure (3) Temperature distribution on the fin 
$\theta=\left(T_{\mathrm{a}}-\mathrm{T}_{\mathrm{s}}\right)$ is smaller for a wet fin than for a dry one. Thus, the surface temperature increases when there is moisture condensation. The higher relative humidity leads to high temperature on the fin surface from fin base to fin tip due to latent heat of vaporization coming into play for a wet fin. Therefore, the temperature gradient at the tip for a dry fin is greater than that for the wet fin. The figure shows the comparison with the temperature distribution of onedimensional longitudinal fin solved analytically by [7].

In figure $(4, a, b)$, fin efficiency and fin effectiveness estimated by the present model are plotted against the length of fin. The fin efficiency decreases while fin effectiveness increases with the increase in the length of fin, since the increase in length of fin leads to increase in the range of temperature in the fin for which reduces the fin efficiency. Also this clarification can be shown in figure (5).

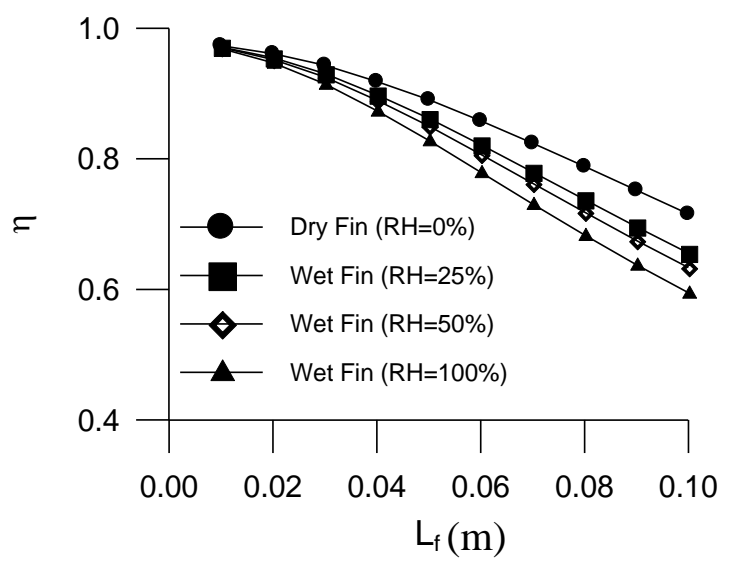

( a )

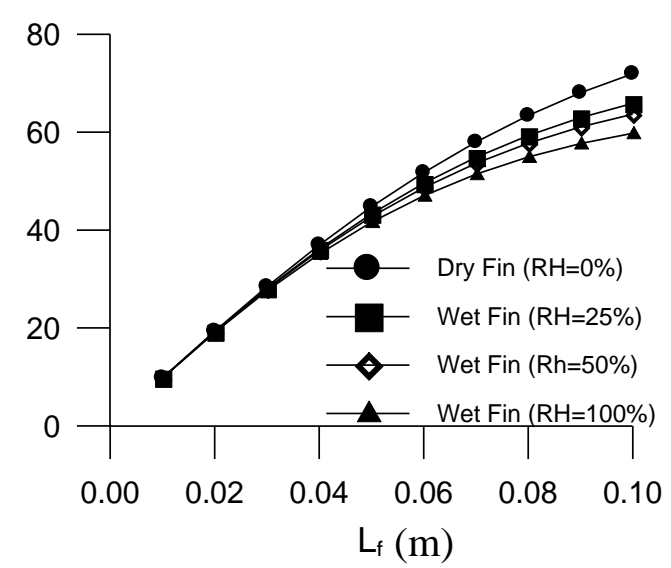

( b )

Figure (4) Variation of fin performance parameters of longitudinal fin with the length of fin at different relative humidity (a) fin efficiency (b) fin effectiveness

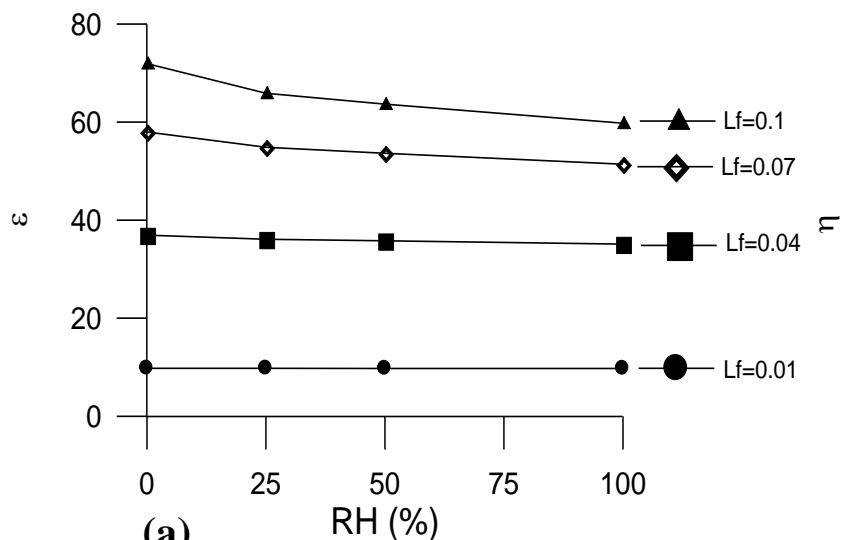

(a)

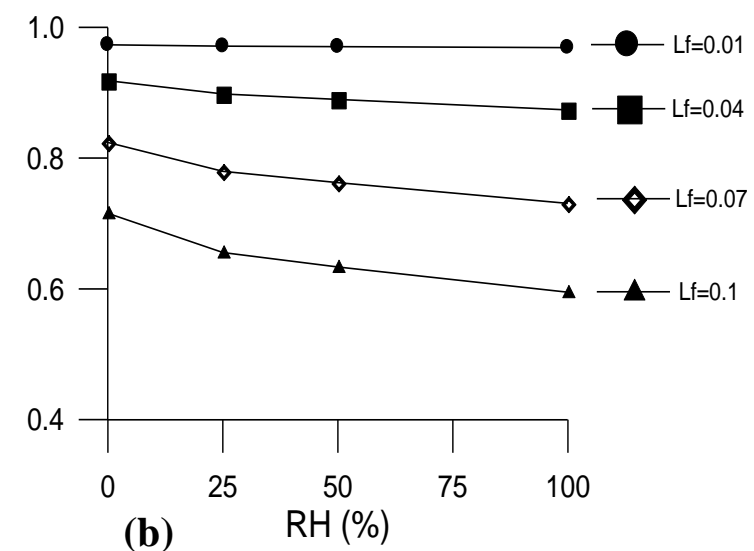

(b)

Figure (5), Variation of fin effectiveness and efficiency of longitudinal fin with the relative humidity at different length of fin: (a) fin effectiveness (b) fin efficiency 
Figure (6) represents the fin efficiency against the relative humidity at different atmospheric pressures. It's clear that the fin efficiency increases with the increases in the atmospheric pressure. When the atmospheric pressure increases the humidity ratio of air will increase.

Figure (7) shows the relation between the heat flux against the length of fin at range of relative humidity of $(0,25,50$ and 100$) \%$ for the longitudinal fin. At constant relative humidity, the increase in length of fin lead to increase in the heat flux because the increase in the surface area of fin. When the relative humidity increases, the heat flux also increases because the surface temperature increases when there is moisture condensation. The higher relative humidity leads to high heat transfer on the fin surface along the fin.

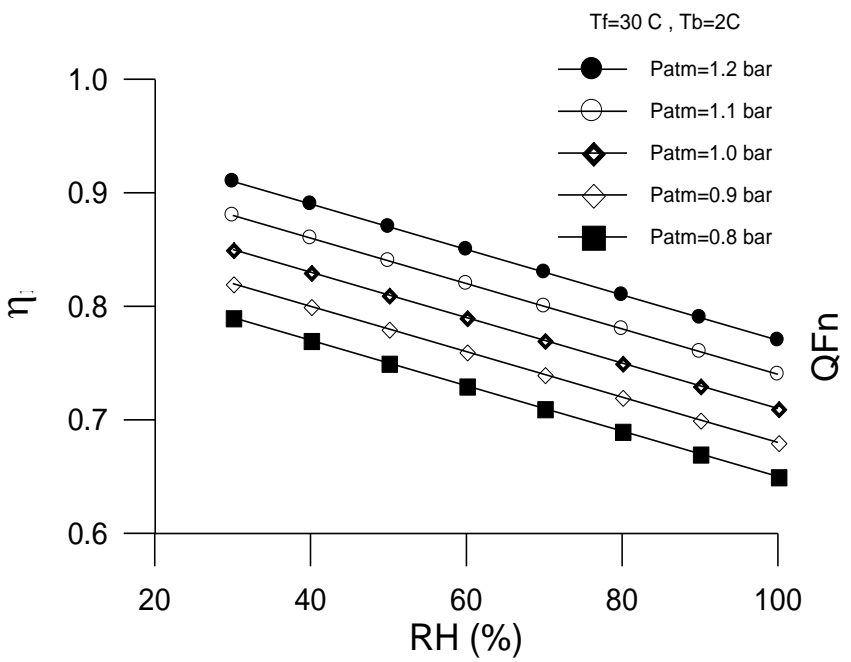

Figure (6), Fin efficiency of longitudinal fin against the relative humidity at different atmospheric pressure.

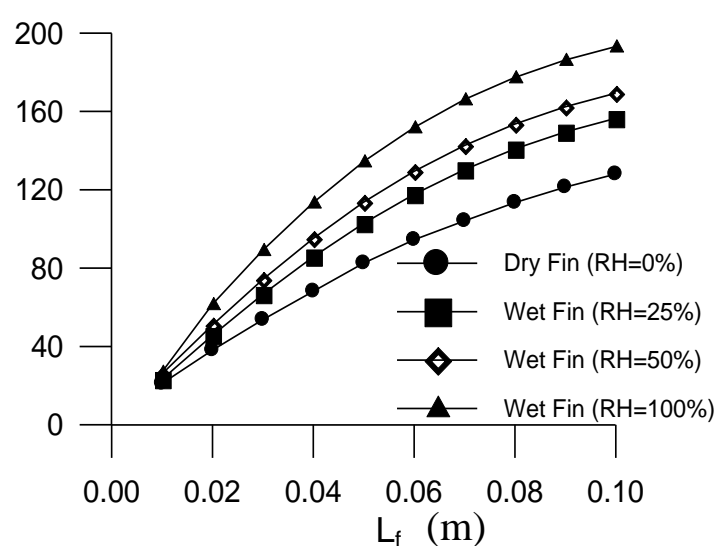

Figure (7) Heat flux against the length of fin

\section{Conclusions:}

In this paper, the two dimensional heat equation for longitudinal fins exposed to fully wet air conditions has been solved numerically using some simplified assumptions. The study included both dry and wet conditions of fin. The following general conclusions can be drawn from this study:

1-The temperature gradient at the tip for a dry fin is greater than that for the wet fin and the increase in relative humidity increases the fin surface temperature.

2-For fully wet fin and at the same length of fin, the fin efficiency and fin effectiveness are decreases with the increase of the relative humidity.

3-For fully wet fin, the fin efficiency depends on the atmospheric pressure. When the atmospheric pressure increases the fin efficiency also increases.

4-For fully wet fin, the increase in the relative humidity lead to increase in the heat transfer. 


\section{References:}

[1] Rosario L., Rahman M.M., "Overall Efficiency of a Radial Fin Assembly Under Dehumidifying Conditions", ASME, Journal of Energy Resources Technology120, (1998) 299-304.

[2] Wu G., Bong T.Y., "Overall Efficiency of a Straight Fin with Combined Heat and Mass Transfer", ASHRAE Transactions 100 (1994) 367-374, part I.

[3] Kundu, B. "An Analytical Study of The Effect of Dehumidification of Air on the Performance and Optimization of Straight Tapered Fins", Int. Commun. Heat Mass Transfer 29 (2002) 269-278.

[4] Kundu B., Das P.K., "Performance and Optimization Analysis for Fins of Straight Taper with Simultaneous Heat and Mass Transfer", Transaction of the ASME 126 (2004) 862-868.

[5] Naphon P., "Study on the Heat Transfer Characteristics of the Annular Fin Under Dry-Surface, Partially Wet-Surface, and Fully Wet-Surface Conditions", International Communications in Heat and Mass Transfer 33 (2006) 112-121.

[6] Sharqawy M.H., Zubair S.M., "Efficiency and Optimization of Longitudinal Fin with Combined Heat and Mass Transfer - an analytical solution", Int. J. Refrig. 30 (2007), 751-757.

[7] Sharqawy M.H., Zubair S.M., "Combined Heat and Mass Transfer Analysis From Annular Fins of Constant Cross-Sectional Area", in: 8th International Symposium on Advances in Computational Heat Transfer Proceedings, ICHMT, Marrakech, Morocco, Paper\# CHT-08-239, May 2008.

[8] Kundu B. and Barman D., "Analytical Study on Design Analysis of Annular Fins Under Dehumidifying Conditions with a Polynomial Relationship Between Humidity Ratio and Saturation Temperature", International Journal Heat and Fluid Flow (2010)

[9] Goodarzian H., Sahebi S.A.R., M., Omran S. and Safaee J." A Collocation Solution on the Optimization of Straight Fin with Combined Heat and Mass Transfer", International Journal of the Physical Sciences, Vol. 6(9), pp. 22682274, 4 May, 2011

[10] Jin F. M., Bo W., Shi B. G. and Xu, H. "Numerical Research and Optimization Analysis on Straight Rectangular Fin with Combined Heat and Mass Transfer", Journal of International Conference on E-Business and E-Government, pp.1-4, 2011.

[11] Jin F. M., Bo, W., Shi B.G. and Lu Y. S.," 2-D Numerical Analysis of Fin Efficiency on Straight Rectangular Fin with Combined Heat and Mass Transfer", Applied Mechanics and Material, Vol. 105-107, pp.2117-2120, 2012. 